\title{
DETERMINAÇÃO DO LIMITE DE LIQUIDEZ EM DOIS TIPOS DE SOLO, UTILIZANDO-SE DIFERENTES METODOLOGIAS
}

\author{
Cristiano Márcio Alves de Souza ${ }^{1}$, Leidy Zulys Leyva Rafull ${ }^{2}$ \& Luciano Baião Vieira ${ }^{3}$
}

\begin{abstract}
RESUMO
Neste trabalho desenvolveu-se um estudo sobre a da determinação do limite de liquidez em dois Latossolos, um com textura muito argilosa, proveniente da cidade de Viçosa, MG, e outro com textura franco-argilo-arenosa, oriundo da cidade de Paraopeba, MG. Foram utilizados quatro métodos de determinação: o de Casagrande padrão, o de Casagrande com um ponto, o de penetrômetro de cone e o de penetrômetro de cone com um ponto. Analisou-se o limite de liquidez de ambos os solos, sendo que o proveniente de Viçosa apresentou maior valor que o de Paraopeba, em todos os métodos. Dos métodos utilizados no solo muito argiloso, apenas o de penetrômetro de cone com um ponto apresentou diferença significativa, enquanto para o solo franco-argilo-arenoso não houve diferença significativa entre os métodos de determinação do limite de liquidez; assim, quanto maior a porcentagem da fração tamanho argila no solo, maior é sua influência nos métodos de determinação do limite de liquidez.
\end{abstract}

Palavras-chave: limite de liquidez, penetrômetro de cone, aparelho de Casagrande

\section{DETERMINATION OF LIQUID LIMIT IN TWO TYPES OF SOILS USING DIFFERENT METHODS}

\begin{abstract}
A study concerning the determination of liquid limit was conducted for two types of Latosols. Four methods of determination were used: Casagrande, Casagrande one-point, cone penetrometer and one-point cone penetrometer. The liquid limit was analyzed for both the soils: one originated from the City of Viçosa, MG (with high content of clay particles) and another from Paraopeba, MG (sandy clay loam). The soil from Viçosa presented high values of liquid limit in all methods. Among the used methods, only the one-point Cone Penetrometer method presented a significant difference. There was no significant difference in the determination methods of liquid limit for the other soil. Thus, the content of clay size in the soil has an influence on the methods of determination of the liquid limit.
\end{abstract}

Key words: liquid limit, cone penetrometer, Casagrande apparatus

\footnotetext{
Recebido 05/04/2000, Protocolo 039/00

${ }^{1}$ Mestrando em Engenharia Agrícola, DEA-UFV, Campus da UFV, CEP 36571 - 000, Viçosa, MG. Fone: (0xx31) 899 1860, Fax: (0xx31) 899 2735. E-mail: csouza@alunos.ufv.br

${ }^{2}$ Doutoranda em Engenharia Agrícola, DEA-UFV.E-mail: zulys@alunos.ufv.br

${ }^{3}$ Professor Adjunto, DS, Departamento de Engenharia Agrícola da UFV. Fone: (0xx31) 899 1879. E-mail: 1baiao@mail.ufv.br
} 


\section{INTRODUÇÃO}

O solo é o meio físico que serve de suporte, proporciona água, ar e elementos nutritivos às plantas. Ele suporta, de maneira passiva, a passagem das máquinas agrícolas e resiste às forças de tração dos tratores e à ação dos implementos. No campo das construções rurais é o meio em que se assentam as estruturas e o material básico das obras de terra.

Trabalhando com solos, seja para tráfego de máquinas ou construções, é importante caracterizá-lo para que se tenha segurança na execução dessas operações; solos que apresentam, em sua forma textural, alta porcentagem de finos, são muito influenciados pela umidade, além da forma das partículas e da sua composição química e mineralógica, causando grandes variações nas suas propriedades plásticas. Segundo Oliveira et al. (1997) nessas circunstâncias não basta uma análise granulométria para caracterizá-los.

Caputo (1994) cita que o comportamento plástico do solo depende das características das forças de tensão-deformação a ele imposta, porém esse mesmo autor relata as dificuldades na determinação dessas propriedades.

A consistência do solo é uma das características mais importantes para a engenharia, pois determina o comportamento do solo ante determinadas tensões e deformações; outrossim, o grau de consistência do solo exerce considerável influência sobre o regime de água no mesmo, afetando a condutividade hidráulica e permitindo fazer-se inferências sobre a curva de umidade; além do mais, é determinante na resistência do solo à penetração e na compactação e seu conhecimento possibilita a determinação do momento adequado do uso de técnicas que favoreçam um bom manejo do solo, propiciando melhor conservação do mesmo, além de diminuir a demanda energética nas operações mecanizadas.

Em 1911 foram definidos, pelo cientista sueco A. Atterberg, certos limites que delimitam o intervalo de consistência do solo, denominados limite de liquidez e de plasticidade.

Tradicionalmente, para a determinação do limite de liquidez o método mais utilizado é aquele padronizado por Arthur Casagrande, que utiliza o aparelho desenvolvido pelo mesmo. Com esse mesmo fim, tem sido muito utilizado na Inglaterra e, nos últimos anos, no Brasil, o penetrômetro de Cone.

Desde 1930 Baver já citava a importância dos limites de Atterberg como indicador das propriedades e forças físicas envolvidas em problemas de preparo do solo, atribuindo valor considerável à determinação da consistência do solo, por meio desses limites, ressalta-se que os valores do limite de liquidez e do limite de plasticidade são utilizados para se determinar o índice de plasticidade de um solo. Segundo Oliveira et al. (1997) outros índices podem ser estabelecidos ou, ainda, ter correlação direta com os mesmos, dentre os quais podem ser citados: índice de liquidez, limite de contração, friabilidade máxima e mínima, índice de friabilidade, coeficiente de extensão linear (cote) e índice de atividade da argila. Sewell \& Mote (1969) afirmam também que o limite de liquidez pode ser um indicador da permeabilidade do solo.

Em estudos geotécnicos, a correlação entre o limite de liquidez e o limite de plasticidade, tem grande aplicação em avaliações de solo para uso em fundações, construções de estradas e estruturas para armazenamento e retenção de água (Mbagwu \& Abeh, 1998).
Balastreire (1990) cita que o fluxo plástico é uma condição de falha do solo, da mesma forma que o cisalhamento, tração e compressão, e para o qual não existe ainda um modelo matemático para caracterizá-lo, sendo utilizado o limite de liquidez e de plasticidade para designá-lo.

Atterberg, citado por Renedo (1996) comprovou que, a medida em que aumenta o conteúdo de argila do solo, aumentam também os valores do índice de plasticidade; desta forma, quanto maior é a relação da superfície total das partículas de argila em relação ao seu volume, maior número de moléculas de água é capaz de absorver e, por conseguinte, serão mais elevados os valores dos limites de Atterberg.

Devido à importância do conhecimento do limite de liquidez na caracterização do solo, o objetivo deste trabalho foi determinar o limite de liquidez de dois tipos de solo, utilizando-se comparativamente quatro métodos: o de Casagrande padrão, o de Casagrande com um ponto, o de penetrômetro de cone e o de penetrômetro de cone com um ponto.

\section{MATERIAL E MÉTODOS}

Os ensaios foram conduzidos no Laboratório de Mecânica dos Solos dos Departamentos de Engenharia Agrícola e Engenharia Civil da Universidade Federal de Viçosa, nos quais se analisaram dois Latossolos, um proveniente da cidade de Viçosa, MG, e o outro da cidade de Paraopeba, MG, o primeiro com textura muito argilosa (Solo 1) e o segundo francoargilo-arenosa (Solo 2) cujas características texturais se apresentam na Tabela 1.

Tabela 1. Características texturais dos solos

\begin{tabular}{ccccc}
\hline $\begin{array}{c}\text { Classificação Textural } \\
\text { do Solo }\end{array}$ & $\begin{array}{c}\text { Areia } \\
\text { Grossa }\end{array}$ & $\begin{array}{c}\text { Areia } \\
\text { Fina }\end{array}$ & Silte & Argila \\
\cline { 2 - 5 } & \multicolumn{4}{c}{$\%$} \\
\hline Argiloso & 6 & 3 & 15 & 76 \\
Franco-argilo-arenoso & 43 & 22 & 4 & 31 \\
\hline
\end{tabular}

Na determinação do limite de liquidez foram utilizados quatro métodos: o de Casagrande (met1), o de Casagrande com um ponto (met2), o de penetrômetro de cone (met3) e o de penetrômetro de cone com um ponto (met4).

Montou-se um experimento fatorial $2 \times 4$, sendo dois tipos de solo e quatro métodos de determinação, instalado segundo o delineamento inteiramente casualizado, com três repetições; utilizou-se o teste de Tukey, a nível de 1\% de probabilidade, na comparação dos resultados de limites de liquidez obtidos em cada metodologia.

\section{Preparação das amostras}

O solo foi peneirado em uma peneira de abertura $425 \mu \mathrm{m}$. Retirou-se do solo peneirado uma amostra de $350 \mathrm{~g}$; em seguida, adicionou-se-lhe água destilada, em quantidade suficiente para formar uma pasta uniforme, relativamente consistente, deixando-a em repouso (maturação) por $24 \mathrm{~h}$, em recipiente fechado; após o tempo de maturação, a amostra foi transferida para uma placa de vidro e submetida a um processo de mistura, fazendo-se contínuos movimentos com uma espátula, com o objetivo de homogeneizá-la. A mistura durou 15 min, evitando-se triturar as partículas sólidas do solo e as amostras utilizadas em todos os ensaios foram preparadas pelo mesmo procedimento. 


\section{Método de Casagrande padrão}

Para a determinação do limite de liquidez por este método, primeiramente foi calibrado o aparelho de Casagrande; usou-se o calibrador do aparelho, de $1 \mathrm{~cm}$ de espessura, para verificar a altura do ponto mais elevado à base da concha.

Transferiu-se, com uma espátula, parte da amostra para a concha do aparelho de Casagrande e se alisou a superfície, de forma a se obter uma camada com espessura de $10 \mathrm{~mm}$ na seção mais profunda; fez-se uma ranhura ao longo do plano de simetria da concha, utilizando-se o cinzel de Casagrande, que foi mantido normal à concha no ponto de contato durante o movimento; depois, a concha foi colocada no aparelho, evitando-se choques; a manivela foi girada, procurando-se respeitar a razão de duas revoluções por segundo e foram contados os golpes necessários para que as duas bordas inferiores da ranhura se unissem, numa distância de $13 \mathrm{~mm}$, ao longo do eixo de simetria; seguidamente, foram coletados aproximadamente $20 \mathrm{~g}$ de solo junto às bordas, que se uniram para posterior determinação da umidade.

O material da concha foi retirado para se promover a sua limpeza e secagem. A amostra ensaiada foi misturada novamente ao restante do material preparado, ao qual se adicionou um pouco de água para aumentar a umidade e, em seguida, homogeneizou-se a pasta novamente; este procedimento foi repetido cinco vezes, para se obter 5 pares de valores de umidade versus número de golpes situados, esses últimos, entre 15 e 35.

Os dados foram representados graficamente, com o número de golpes na abscissa e a umidade correspondente na ordenada foi, em seguida, traçada a reta que melhor se ajustou os pontos. A umidade correspondente à projeção de 25 golpes, sobre a reta traçada, foi considerada limite de liquidez.

\section{Método de Casagrande com um ponto}

Este método é uma maneira rápida de se determinar o limite de liquidez do solo, pois somente é necessário fazer-se a medida de um ponto de umidade, porém os resultados podem ser menos precisos que aqueles determinados pelo método de Casagrande padrão. O método é mais usado quando a quantidade do solo disponível é limitada; a aparelhagem utilizada é idêntica àquela usada no método de Casagrande padrão.

Realizou-se a calibração do aparelho procedendo-se, de maneira similar, ao método padrão.

Na realização do ensaio buscou-se trabalhar com a umidade da amostra, de forma que o fechamento da ranhura ocorresse o mais próximo possível de 25 golpes.

Após o ensaio, retirou-se uma amostra para determinação da umidade, expressada com precisão de $0,1 \%$. Este valor foi multiplicado pelo fator correspondente ao número de golpes, para fechamento da ranhura, apresentado na Tabela 2.

\section{Método do penetrômetro de cone}

Para se determinar o limite de liquidez por este método, fez-se primeiro a calibração do penetrômetro de cone e se testou o cone para verificar se sua ponta estava adequadamente afiada e se sua massa pesava aproximadamente $80 \mathrm{~g}$, sendo todos esses requisitos satisfeitos; depois, retirou-se parte da amostra previamente preparada, colocando-a sobre uma superfície de vidro, homogeneizando-a novamente; esta amostra foi colocada na cápsula do aparelho para efetuar-se a medição,
Tabela 2. Fatores para o ensaio de Casagrande com um ponto

\begin{tabular}{ccccc}
\hline $\mathrm{N}^{\text {o }}$ de Golpes & Fator & & $\mathrm{N}^{\mathbf{o}}$ de Golpes & Fator \\
\cline { 5 - 5 } \cline { 5 - 5 } 15 & 0,95 & & 26 & 1,00 \\
16 & 0,96 & & 27 & 1,01 \\
18 & 0,96 & & 28 & 1,01 \\
19 & 0,97 & & 29 & 1,01 \\
20 & 0,97 & & 30 & 1,02 \\
21 & 0,98 & & 31 & 1,02 \\
22 & 0,98 & & 32 & 1,02 \\
23 & 0,99 & & 33 & 1,02 \\
24 & 0,99 & & 34 & 1,03 \\
25 & 1,00 & & 35 & 1,03 \\
\hline
\end{tabular}

Fonte: Head (1992)

enchendo-a até o topo e pressionando-a contra as paredes e o fundo da cápsula, iniciando-se do centro para as laterais procurando-se, assim, evitar a formação de bolhas de ar dentro da amostra.

Os ensaios só eram iniciados quando a ponta do cone estava tangenciando a superfície da amostra, sendo o aparelho travado e zerado nesse momento; em seguida, foi liberado o cone, penetrando na amostra durante $5 \mathrm{~s}$, programados no temporizador do aparelho. O valor da profundidade de penetração atingida pelo cone foi lido na escala do penetrômetro; retiraram-se aproximadamente $15 \mathrm{~g}$ em torno do ponto de penetração, para determinação de umidade, buscando-se que o intervalo de valores de penetração do cone na amostra estivesse na faixa de 15 a $25 \mathrm{~mm}$.

O solo restante na cápsula foi retirado e agregado ao restante da amostra contida na placa de vidro; em seguida, adicionou-se um pouco de água, formando-se uma nova pasta, para a qual se repetiu o ensaio. Este procedimento foi realizado três vezes, obtendo-se quatro pares dos valores penetração e umidade, para cada repetição.

Representou-se, num gráfico, a leitura da penetração na ordenada e a umidade na abscissa; depois, traçou-se a reta que melhor se ajustou aos pontos e o valor de umidade correspondente a $20 \mathrm{~mm}$ de penetração foi considerado limite de liquidez.

\section{Método do penetrômetro de cone com um ponto}

Este método foi desenvolvido por Clayton \& Jukes em 1978, como método alternativo na determinação do limite de liquidez, quando a quantidade de solo disponível não é apropriada à aplicação do método-padrão.

A aparelhagem é a mesma usada no teste de quatro pontos e o procedimento é também idêntico, exceto que menor quantidade (100 g) de solo é requerida; por outro lado buscou-se, na realização do ensaio, adequar a umidade da amostra, de maneira que a penetração do cone se aproximasse o máximo possível de $20 \mathrm{~mm}$.

Após a determinação de dois valores consecutivos da profundidade de penetração, retirou-se o solo da região penetrada, para determinar a umidade, que foi expressa com precisão de $0,1 \%$ e, só então, multiplicada por um fator apresentado na Tabela 3 obtendo-se, assim, o limite de liquidez do solo; a tabela indica, também, a que grupo de plasticidade o solo pertence. 
Tabela 3. Fatores para o ensaio de penetrômetro de cone com um ponto

\begin{tabular}{cccc}
\hline \multirow{2}{*}{$\begin{array}{c}\text { Penetração } \\
(\mathrm{mm})\end{array}$} & Alta & Intermediária & Baixa \\
\cline { 2 - 4 } & 1,098 & 1,094 & 1,057 \\
15 & 1,075 & 1,076 & 1,052 \\
16 & 1,055 & 1,058 & 1,042 \\
17 & 1,036 & 1,039 & 1,030 \\
18 & 1,018 & 1,020 & 1,015 \\
19 & 1,001 & 1,001 & 1,000 \\
20 & 0,984 & 0,984 & 0,984 \\
21 & 0,967 & 0,968 & 0,971 \\
22 & 0,949 & 0,954 & 0,961 \\
23 & 0,929 & 0,943 & 0,955 \\
24 & 0,909 & 0,934 & 0,954 \\
25 & \multirow{2}{*}{ Acima de 50\% } & Entre & \multirow{2}{*}{ Abaixo de 35\% $50 \%$} \\
\hline Umidade & \multicolumn{3}{c}{}
\end{tabular}

\section{Determinação da umidade do solo}

Após a realização de cada ensaio retiraram-se amostras, como descrito em cada método e, para a determinação do teor de umidade, utilizou-se o método em estufa, a $105^{\circ} \mathrm{C}$, por $24 \mathrm{~h}$.

\section{RESULTADOS E DISCUSSÃO}

As médias do limite de liquidez determinadas através das quatro metodologias, são apresentadas na Tabela 4.

Tabela 4. Valores médios de limite de liquidez $(\%)$

\begin{tabular}{lccccc}
\hline \multirow{2}{*}{ Solo } & \multicolumn{2}{c}{ Casagrande } & \multicolumn{2}{c}{ Penetrômetro } \\
\cline { 2 - 3 } \cline { 5 - 6 } & Padrão & Um Ponto & & Padrão & Um Ponto \\
\hline Argiloso & 73,90 & 73,48 & & 73,06 & 69,73 \\
Franco-argilo-arenoso & 26,08 & 25,53 & & 26,78 & 26,46 \\
\hline
\end{tabular}

A Tabela 5 apresenta a análise de variância dos dados obtidos nos ensaios, mostrando que houve diferença significativa entre os solos e metodologias, e a interação entre os dois.

Tabela 5. Análise de variância do limite de liquidez

\begin{tabular}{lcrrc}
\hline FV & GL & \multicolumn{1}{c}{ SQ } & \multicolumn{1}{c}{ QM } & \multicolumn{1}{c}{ F } \\
\hline Efeito do Solo (S) & 1 & 12879,98 & 12879,98 & $14493,41^{* *}$ \\
Efeito do Método (M) & 3 & 13,93 & 4,64 & $5,22^{*}$ \\
Efeito S x M & 3 & 21,37 & 7,12 & $8,02^{* *}$ \\
Tratamento & 7 & 12915,28 & & \\
Resíduo & 16 & 14,22 & 0,89 & \\
Total & 23 & 12929,49 & & \\
\hline
\end{tabular}

* Significativo a $5 \%$ de probabilidade pelo Teste $\mathrm{F}$

** Significativo a $1 \%$ e probabilidade pelo Teste $\mathrm{F}$

A diferença significativa entre os solos foi devido, à diferença textural, sendo que o solo com textura muito argilosa apresentou maior limite de liquidez em todos os métodos, como se pode observar na Tabela 4.

Entre os métodos, a diferença significativa ocorreu, provavelmente, pela diferença nos procedimentos de obtenção do limite de liquidez, por ser indireta a determinação para os métodos por um ponto; por outro lado, também houve diferença significativa na interação, mostrando que os fatores solos e métodos não atuam independentemente, existindo o efeito do solo em cada método e vice-versa, o que levou à necessidade de se estudar os fatores, de maneira isolada (Tabela 6 e 7).

Tabela 6. Desdobramento da interação, com solo dentro do método

\begin{tabular}{lrrrc}
\hline \multicolumn{1}{c}{ FV } & GL & SQ & QM & \multicolumn{1}{c}{ F } \\
\hline Método & 3 & - & - & - \\
Solo (Met1) & 1 & 3431,35 & 3431,35 & $3861,18^{* *}$ \\
Solo (Met2) & 1 & 3449,46 & 3449,46 & $3881,56^{* *}$ \\
Solo (Met3) & 1 & 3204,33 & 3204,33 & $3605,72^{* *}$ \\
Solo (Met4) & 1 & 2808,50 & 2808,50 & $3160,32^{* *}$ \\
Resíduo & 16 & 14,22 & 0,89 & \\
Total & 23 & & & \\
** Significativo a 1\% de Probabilidade pelo Teste F & \\
$\quad$ Solo(Met) - Estudo da influência dos solos dentro dos métodos
\end{tabular}

Tabela 7. Desdobramento da interação, com método de determinação de limite de liquidez dentro de solo

\begin{tabular}{lcrrc}
\hline FV & GL & SQ & QM & F \\
\hline Solo & 1 & & & \\
Método (Solo 1) & 3 & 32,69 & 10,90 & $12,26^{* *}$ \\
Método (Solo 2) & 3 & 2,61 & 0,87 & 0,98 \\
Resíduo & 16 & 14,22 & 0,89 & \\
Total & 23 & & \\
** Significativo a 1\% de Probabilidade pelo Teste F \\
$\quad$ Método (Solo) - Estudo da influência dos métodos dentro dos solos
\end{tabular}

A análise de variância apresentada na Tabela 6 mostra que ocorreu diferença significativa entre os solos, em todos os métodos, e que o solo com textura muito argilosa apresentou maior valor de limite de liquidez nos quatro métodos (Tabela 4).

Verificou-se diferença significativa dos métodos dentro do solo com textura muito argilosa, o mesmo não acontecendo para o outro solo, conforme observado na análise de variância apresentada na Tabela 7; portanto, o limite de liquidez do solo muito argiloso foi influenciado pelos métodos, tendo cada método influência distinta na sua determinação.

As médias do limite de liquidez do solo muito argiloso foram analisadas apresentando diferença significativa a $1 \%$ de probabilidade, pelo teste de Tukey. Observa-se, na Tabela 8 , que somente o limite de liquidez determinado pelo método de penetrômetro de cone com um ponto diferiu significativamente dos demais, mostrando que o método influencia diretamente no resultado. O resultado do ensaio desse método será mais preciso quanto mais próximo de $20 \mathrm{~mm}$ estiver a profundidade de penetração.

Tabela 8. Análise de médias* do limite de liquidez obtidas com os quatro métodos para o solo muito argiloso, pelo teste de Tukey

\begin{tabular}{lc}
\hline Método & Limite de Liquidez \\
\hline Casagrande Padrão & $73,90 \mathrm{a}$ \\
Casagrande com um ponto & $73,48 \mathrm{a}$ \\
Penetrômetro de Cone & $73,06 \mathrm{a}$ \\
Penetrômetro de Cone com um ponto & $69,73 \mathrm{~b}$ \\
\hline "Letras iguais indicam que as médias não diferem significativamente pelo teste de Tukey a $1 \%$ de
\end{tabular}

Letras iguais indicam que as médias não diferem significativamente pelo teste de Tukey a $1 \%$ de probabilidade 


\section{CONCLUSÕES}

1. O solo muito argiloso apresentou maior limite de liquidez que o solo franco-argilo-arenoso em todos os métodos.

2. Quanto maior for a porcentagem da fração argila no solo, maior influência terá sobre o método de determinação do limite de liquidez.

3. Somente o método de penetrômetro de cone com um ponto apresentou diferença significativa na determinação do limite de liquidez do solo muito argiloso, quando comparado com os demais métodos.

4. Os métodos de determinação do limite de liquidez por um ponto podem ser utilizados em solos que não apresentem elevada porcentagem da fração argila.

\section{REFERÊNCIAS BIBLIOGRÁFICAS}

BALASTREIRE, L.A. Máquinas agrícolas. São Paulo: Editora Manole LTDA, 1990.307p.
CAPUTO, H.P. Mecânica dos solos e suas aplicações. $6^{\mathrm{a}}$ ed. Rio de Janeiro: LTC Editora S.A., 1994. 225p.

HEAD, K.H. Manual of soil laboratory testing. New York: J. Wiley, 1992.388p.

MBAGWU, J.S.C.; ABEH, O.G. Prediction of engineering properties of tropical soils using intrinsic pedological parameters. Soil Science, Baltimore, v.163, n.2, p.93-102, 1998.

OLIVEIRA, M.L.; GEDANKEN, A.; RUIZ, H.A. Utilização do penetrômetro de cone na determinação do limite de liquidez em latossolos. In: CONGRESSO BRASILEIRO DE ENGENHARIA AGRÍCOLA, 26, 1997, Campina Grande. Anais... Sociedade Brasileira de Engenharia Agrícola, 1997. CD Rom.

RENEDO, V.S.G. Dinámica y mecánica de suelos. Madrid: Ediciones Agrotécnicas, S.L., 1996. 426p.

SEWELL, J. I.; MOTE, C.R. Liquid-limit determination for indicating effectiveness of chemicals in pond sealing. Transaction of the ASAE, St. Joseph. v.12, n.5, p.611-613, 1969. 